\title{
Elementary Algebra on Vedic Mathematics
}

\author{
Krishna Kanta Parajuli \\ Department of Mathematics, Valmeeki Campus, Nepal Sanskrit University \\ Email: kknmparajuli@gmail.com
}

\begin{abstract}
The South Asian region has a long history of discovering new ideas, ideologies, and technologies. Since the Vedic period, the land has been known as a fertile place for innovative discoveries. The Vedic technique used by Bharati Krishna Tirthaji is unique among South Asian studies. The focus of this study was mostly on algebraic topics, which are typically taught in our school level. The study also looked at how Vedic Mathematics solves issues of elementary algebra using Vedic techniques such as Paravartya Yojayet, Sunyam Samyasamuccaye, Anurupye Sunyamanyat, Antyayoreva and Lopanasthapanabhyam. The comparison and discussion of the Vedic with the conventional techniques indicate that the Vedic Mathematics and its five unique formulas are more beneficial and realistic to those learners who are experiencing problems with elementary level algebra utilizing conventional methods.
\end{abstract}

Keywords: Elementary Algebra, Paravartya Yojayet, Sunyam Samyasamuccaye, Anurupye Sunyamanyat, Antyayoreva, Lopanasthapanabhyam

\section{Introduction}

The word 'Algebra' was originated from the corruption of the Arabic word 'Al-jabar'al-muqabulah' where 'al' means 'the', 'jabr' refers to the operation of transferring a quantity from one side of an equation to another while 'muqabulah' means the process of subtracting similar quantities from both sides of an equation (Sidhu, 1990). Algebra is either a form of mathematics in which letters and symbols are used to represent numbers or a generalization of arithmetic in which numbers are represented by letters that are combined according to arithmetic rules (Hoad, 1996). The numbers are often represented by the symbols called variables. Its concepts are often required in teaching and learning to return to corresponding circumstances in Arithmetic. As a generalized arithmetic, it can be linked to geometry by claiming that algebra is only written geometry and geometry is only pictured algebra (Sidhu, 1990).

Generally speaking, algebra can be divided into two levels: elementary and abstract. Elementary Algebra is the most fundamental part of algebra that is commonly considered to be essential for any study of mathematics and its applications, i.e., the part of algebra that is typically taught in elementary mathematics courses (Cajori, 1919). The more abstract part of algebra is known as 
Abstract Algebra or Modern Algebra which extends the familiar concepts found in elementary algebra to more general concepts. Abstract Algebra or Modern Algebra is mainly studied by trained mathematicians, and it involves the axiomatic definition and investigation of algebraic structures such as Groups, Rings, and Fields (Menini \& Oystaeyen, 2017).

Algebra's origins can be traced back to the ancient Babylonians, who developed it as an advanced arithmetical device. In the same period, the Egyptians, Greeks, and Chinese formed linear and quadratic equations (Struik, 1987; Plofker, Imhausen, Robson, \& Dauben, 2007).

It is considered that, before $300 \mathrm{BC}$ the Bijganit (बीजगणित) was derived from the Bakhshali Manuscript (वाक्शाली लिपि) (Parajuli, 2021). At that time, the Bijganit became one of the most influential practice and widely spread throughout the continent. In pre-medieval era (500 BC - $400 \mathrm{AD})$ the development of Bijganit took place rapidly as mathematicians were putting their hard and continuous effort upon it. Further development of arithmetic and Bijganit took place in the later time of the medieval era (400 AD - $1200 \mathrm{AD}$ ) which then got spread to Arab and other countries. (Parajuli, 2021; Acharya, 2015; Boyer, 1991). Brahmagupta (598 AD $668 \mathrm{AD}$ ) was a famous South-Asian mathematician and astronomer. He wrote the method of solving linear and quadratic equations in his book Brahmasphutasiddhant (ब्राहम्स्फ़ुटसिद्धान्त) in $628 \mathrm{AD}$ (Parajuli, 2021). It is greatly to the credit of Brahmagupta that he gave all integral solutions of the linear Diophantine equation i.e., $a x+b y=$ c, where a, b and c are constants (Boyer, 1991). Bhaskaracarya-II (1114 AD - 1993 AD) was the famous leading mathematician of ancient Indian during $12^{\text {th }}$ century. Bhaskaracarya wrote Algebra in his Siddhantasiromani (Patwardhan, Naimpally \& Singh, 2015). Hence, talking about the development of algebra, the South Asian region has a long tradition of inventing new ideas, principles, and inventions. Since the Vedic period, the land has been regarded as a fertile ground for new inventions (Parajuli, 2021; Groza, 1968).

Many eastern and western mathematicians contributed to the modernization of mathematics. They contributed to the subject of algebra as well as other areas of mathematics. South Asian mathematicians have made a significant contribution to these fields (Groza, 1968; Struik, 1987). Furthermore, Bharati Krishna Tirthaji (1884 AD - 1960 AD), a South Asian glorious and divine human, made a significant contribution to the development of mathematics in the nineteenth century (Tirthaji, 2015). He is well-known for rediscovering and reconstructing the new ideas of mathematics from ancient Sanskrit text Veda early last century between $1911-1918$ is popularly known today is Vedic Mathematics (Parajuli, 2021). The Vedic method, he claims, is based on sixteen formulas and an equal number of sub-formulas that cover all branches of mathematics, both pure and applied (Patwardhan, Naimpally \& 
Singh, 2015; Parajuli, 2021).

Out of two levels of algebra, abstract algebra and its problems are not addressed in this article. This paper concentrated solely on the fundamental level of algebra, which are generally required in elementary mathematics courses. Furthermore, this paper focused on how Vedic Mathematics uses Vedic techniques for effectively solving these levels of problems. There are two types of techniques in Vedic Mathematics: specific and general. This paper consists of specific parts with the Vedic formulas as Paravartya Yojayet (परावर्त्यं योजयेत्), Sunyam Samyasamuccaye (शून्यं साम्यसमुच्चये), Anurupye Sunyamanyat (आनुरूप्ये शून्यमन्यत्), Antyayoreva (न्त्ययोरेव) and Lopanasthapanabhyam (लोपस्थापनाभ्याम्) which are the most commonly used for elementary algebraic solutions.

\section{Use of Vedic Formulas in Elementary Algebra}

Vedic Mathematics is a system of reasoning and mathematical working based on ancient mathematical concept as well as modern concepts with precise unique techniques based on its formulas with simple rules and principles (Parajuli, 2021; Tirthaji, 2015). Many Vedic formulas can be used to solve algebraic problems. This paper does not include all Vedic formulas. Only those that are appropriate for some specific fundamental algebraic operations have been selected.

\section{Parāvartya Yojayet (परावर्त्यं योजयेत्)}

The literal meaning of the formula Paravartya Yojayet is "Transpose and apply" (Tirthaji, 2015). This formula is used in algebraic division, solve simple linear, quadratic, cubic equations, partial fractions of algebraic expressions etc. (Parajuli, 2021; Tirthaji, 2015; Parajuli, Jha, Acharya, \& Maske, 2020; Williams, 2019).

\section{(i) Use of Paravartya Yojayet for algebraic division.}

Let $\mathrm{f}(\mathrm{x})=\mathrm{a}_{0} \mathrm{x}^{\mathrm{n}}+\mathrm{a}_{1} \mathrm{x}^{\mathrm{n}-1}+\mathrm{a}_{2} \mathrm{x}^{\mathrm{n}-2}+\ldots+\mathrm{a}_{\mathrm{n}},\left(\mathrm{a}_{0} \neq 0\right)$. Let $\mathrm{f}(\mathrm{x})$ is divided by $\mathrm{g}(\mathrm{x})$, then $\mathrm{f}(\mathrm{x})=\mathrm{Q}(\mathrm{x}) \cdot \mathrm{g}(\mathrm{x})+\mathrm{R}$; where, $\mathrm{Q}(\mathrm{x})$ is quotient, $\mathrm{R}$ is remainder, $\mathrm{f}(\mathrm{x})$ is dividend and $\mathrm{g}(\mathrm{x})$ is divisor.

In the illustrated figure below, the last row will formulate the quotient and remainder pieces. The highest degree of $\mathrm{Q}(\mathrm{x})$ is equal to . The remainder $(\mathrm{R})$ is determined by the number of terms on $\mathrm{g}(\mathrm{x})$. If $\mathrm{g}(\mathrm{x})$ has $\mathrm{m}$ terms, the remainder parts is taken from the right most m columns, and the quotient parts are taken from the left most part. The path of arrows can be used to understand algebraic division procedures, as seen in the illustration below (Tirthaji, 2015; Williams, 2019; Dave, et al., 2018). 
Division of $5 x^{4}-8 x^{2}-15 x-6$ by $x-2$ can be presented as follows.

\begin{tabular}{|l|l|l|l|l|l|}
\hline $\mathrm{x}-2$ & $5 \mathrm{x}^{4}$ & $+0 . \mathrm{x}^{3}$ & $-8 \mathrm{x}^{2}$ & $-15 \mathrm{x}$ & -6 \\
\hline 2 & 5 & 0 & -8 & -15 & -6 \\
\hline & & & & & \\
\hline
\end{tabular}

Here, $Q(x)=5 x^{3}+10 x^{2}+12 x+9 ;$ Remainder $(R)=12$

The method is easily extended to the case where the divisor is a quadratic. For example, the division $\mathrm{x}^{4}-\mathrm{x}^{3}+\mathrm{x}^{2}+3 \mathrm{x}+5$ by $\mathrm{x}^{2}-\mathrm{x}-1$ can be presented as follows.

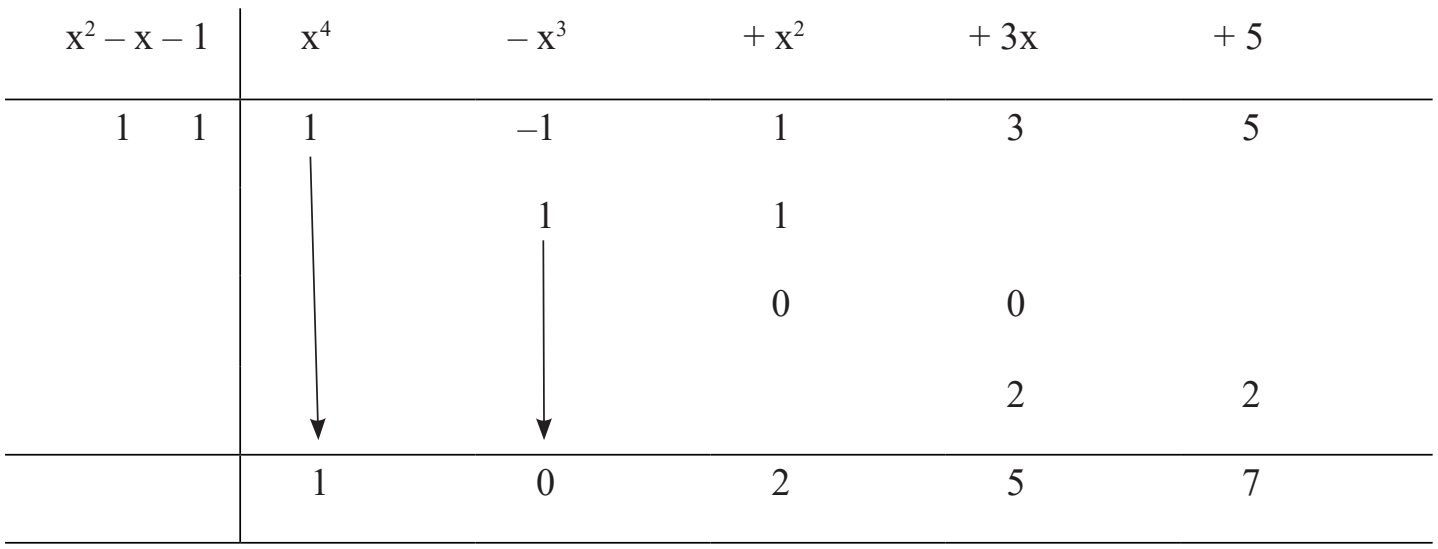

$\therefore$ Quotient $(Q)=x^{2}+2$ and Remainder $(R)=5 x+7$.

\section{(ii) Use of Paravartya Yojayet formula to solve simple equations}

Paravartya formula can be used for special types of simple equations by merging RHS into LHS under the different types of headings. If the sum of the numerators on LHS is equal to the single numerator on RHS, for example $\frac{2}{x+3}+\frac{5}{x+4}=\frac{7}{x+2}$ i.e., $N_{1}(2)+N_{2}(5)=N(7)$, then we apply the formula (where $\mathrm{N}_{1}, \mathrm{~N}_{2}$ have their usual meaning in Mathematics).

The merging procedure of RHS into LHS (Tirthaji, 2015; Parajuli, Jha, Acharya, \& Maskey, 2020; Parajuli, Jha, Acharya, \& Maskey, 2019).

- For merging RHS into LHS, we subtract the independent part of denominators of RHS from the independent part of denominators of LHS and multiply it to the 
respective part of their numerators of LHS.

- As the work of merging has been completed, we put zero on RHS and by simple cross-multiplication we obtain the result of $\mathrm{x}$.

$$
\text { Therefore, } \frac{2 \times(3-2)}{x+3}+\frac{5(4-2)}{x+4}=0 \Rightarrow \frac{2}{x+3}+\frac{10}{x+4}=0 \Rightarrow x=\frac{-19}{6}
$$

We use the same method for three terms as in two terms to merge the RHS of simple equations if $\mathrm{N}_{1}+\mathrm{N}_{2}+\mathrm{N}_{3}$ of LHS $=\mathrm{N}$ of RHS. Consider $\frac{1}{\mathrm{x}+2}+\frac{3}{\mathrm{x}+3}+\frac{5}{\mathrm{x}+5}=\frac{9}{\mathrm{x}+4}$

Here, $\mathrm{N}_{1}(1)+\mathrm{N}_{2}(3)+\mathrm{N}_{3}(5)=\mathrm{N}(9)$. Then, $\frac{1(2-4)}{\mathrm{x}+2}+\frac{3(3-4)}{\mathrm{x}+3}+\frac{5(5-4)}{\mathrm{x}+5}=0$ i.e., $\frac{2}{x+2}+\frac{3}{x+3}=\frac{5}{x+5}$. Again, using the formula as above, we get, $x=\frac{-5}{2}$

\section{(iii) Use of Paravartya Yojayet formula for solving Simultaneous Equations}

Paravartya Yojayet formula for solving simultaneous linear equations of general form as $a_{1} x+b_{1} y=c_{1} ; a_{2} x+b_{2} y=c_{2}$, which would be somewhat similar to Cramer's rule (Tirthaji, 2015; Parajuli, Jha, Acharya, \& Maskey, 2020). The cross-multiplication method to solve simultaneous linear equation which is taught in our presentday curriculum is also similar to the method Paravartya Yojayet (Tirthaji, 2015; Williams, 2019). The Vedic formula moves in a cyclic order.

(iv) Use of Paravartya Yojayet formula in Partial Fraction (Tirthaji, 2015; Williams, 2019).

To find the partial fractions of a proper rational function whose denominator is a product of two or more linear factors. If we have to express $\frac{p x^{2}+q x+r}{(x-a)(x-b)(x-c)}$ in the shape of partial fraction, then we write

$$
\begin{gathered}
\frac{\mathrm{px}^{2}+\mathrm{qx}+\mathrm{r}}{(\mathrm{x}-\mathrm{a})(\mathrm{x}-\mathrm{b})(\mathrm{x}-\mathrm{c})}=\frac{\mathrm{A}}{(\mathrm{x}-\mathrm{a})}+\frac{\mathrm{B}}{(\mathrm{x}-\mathrm{b})}+\frac{\mathrm{C}}{(\mathrm{x}-\mathrm{c})}, \text { where A, B and C are written as, } \\
\mathrm{A}=\frac{\mathrm{px^{2 } + \mathrm { qx } + \mathrm { r }}}{(\mathrm{x}-\mathrm{b})(\mathrm{x}-\mathrm{c})} ; \mathrm{B}=\frac{\mathrm{px}^{2}+\mathrm{q}+\mathrm{r}}{(\mathrm{x}-\mathrm{a})(\mathrm{x}-\mathrm{c})} ; \mathrm{C}=\frac{\mathrm{px}^{2}+\mathrm{qx}+\mathrm{r}}{(\mathrm{x}-\mathrm{a})(\mathrm{x}-\mathrm{b})}
\end{gathered}
$$

For getting the value of $A$ :

- equate the denominator of $A$ to zero, i.e. $x-a=0 \Rightarrow x=a$

- put $x=a$ in $A=\frac{p x^{2}+q x+r}{(x-b)(x-c)}$

- we do similarly for B and C. 


\section{Sunyam Samyasamuccayè (शून्यं साम्यसमुच्चये)}

In Sanskrit Sunnyam means zero, Sammye means equal and Samuccaye means total. Therefore, the meaning of Sunyam Samyasamuccaye is when the Samuccaya is the same, the Samuccaye is zero, i.e. it should be equated to zero. The word Samuccaya has several meanings in different context. This formula is used to solve linear equations, special type of quadratic equations, rational expressions, cubic expressions etc. (Tirthaji, 2015; Williams, 2019; Parajuli, 2019).

Meanings and Applications of Sunyam Samyasamuccaye: The meaning and its corresponding applications of the formula can be expressed as follows.

(i) When Samuccaye is a common factor of unknown quantities in all the terms of linear equation then equate that factor to zero (Parajuli, 2021; Williams, 2019; Parajuli, Jha, Acharya, \& Maskey, 2019).

When $5(x-4)+8(x-4)=3(x-4)-7(x-4)$, where $(x-4)$ is a common factor, so $\mathrm{x}=4$ is the solution.

(ii) When Samuccaye is the product of independent terms in the expression like $(x+a)(x+b)=(x+c)(x+d)$ such that $a b=c d$, then equate the variable to zero (Parajuli, 2021; Tirthaji, 2015; Parajuli, Jha, Acharya, \& Maskey, 2019).

(iii) When Samuccaye is the sum of the denominators of two fractions having the same numerator then equate the sum of the denominators to zero (Parajuli, 2021; Tirthaji, 2015; Parajuli, Jha, Acharya, \& Maskey, 2019). When $\frac{p}{a x+b}+\frac{p}{c x+d}=0($ where, $p \neq 0)$, then the solution is obtained by $(a x+b)+(c x+d)=0$

(iv) When Samuccaye is the sum of the numerators or denominators of the expression like:

$\frac{\mathrm{ax}+\mathrm{b}}{\mathrm{ax}+\mathrm{c}}=\frac{\mathrm{ax}+\mathrm{c}}{\mathrm{ax}+\mathrm{b}}$ where, sum of the numerators $\left(\mathrm{N}_{1}+\mathrm{N}_{2}\right)=$ sum of the denominators $\left(\mathrm{D}_{1}+\mathrm{D}_{2}\right)$

then the value of $\mathrm{x}$ is obtained by equate them to zero (Tirthaji, 2015; Parajuli, Jha, Acharya, \& Maskey, 2019).

(v) When the Samuccaye is the sum of the numerators or denominators/difference of numerator and denominator of the expression like: $\frac{a x+b}{c x+d}=\frac{c x+d}{a x+b}$ where, $\mathrm{N}_{1}+\mathrm{N}_{2}=\mathrm{D}_{1}+\mathrm{D}_{2}=0$, gives the $1^{\text {st }}$ root of the equation and $\mathrm{N}_{1}-\mathrm{D}_{1}=-\left(\mathrm{N}_{2}-\mathrm{D}_{2}\right)=0$, gives the $2^{\text {nd }}$ root of the equation (Parajuli, 2021; Williams, 2019; Parajuli, Jha, Acharya, \& Maskey, 2019). 
When the sum-total of denominator on LHS and RHS are same (having same numerator), then the sum-total equate to zero (Parajuli, 2021; Parajuli, Jha, Acharya, \& Maskey, 2019). For example,

$$
\text { when } \frac{1}{x-b}-\frac{1}{x-b-d}=\frac{1}{x-c+d}-\frac{1}{x-c} \text { i.e., } \frac{1}{x-b}+\frac{1}{x-c}=\frac{1}{x-c+d}+\frac{1}{x-b-d}
$$

where, $\mathrm{D}_{1}+\mathrm{D}_{2}=\mathrm{D}_{3}+\mathrm{D}_{4}=2 \mathrm{x}-\mathrm{b}-\mathrm{c}$. Then, $2 \mathrm{x}-\mathrm{b}-\mathrm{c}=0 \Rightarrow \mathrm{x}=\frac{\mathrm{b}+\mathrm{c}}{2}$

(vi) The expression of the form $\frac{3 x-8}{x-3}+\frac{4 x-35}{x-9}=\frac{2 x-9}{x-5}+\frac{5 x-34}{x-7}$ can be reduced to $\frac{1}{x-3}+\frac{1}{x-9}=\frac{1}{x-5}+\frac{1}{x-7}$. So, can be applied (vi) $)^{\text {th }}$ application (Parajuli, 2021; Parajuli, Jha, Acharya, \& Maskey, 2019).

\section{Anurupye Sunyamanyat (आनुरूप्ये शून्यमन्यत्)}

The meaning of Anurupye Sunyamanyat is "If one is in ratio, the other one is zero". This formula is used to solve particular type of simultaneous linear and quadratic equations. If the ratio of coefficients of one variable is equal to the ratio of their corresponding independent terms of the equation, then another variable is zero (Parajuli, 2021; Tirthaji, 2015; Williams, 2019).

Consider the simultaneous linear equations of two variables: $6 x+7 y=12 ; 5 x+21 y=10$ Here, ratio of coefficient of $x=$ Ratio of independent terms i.e., $\frac{6}{5}=\frac{12}{10}$

$$
\therefore \mathrm{y}=0 \text { then } \mathrm{x}=2 \text {. }
$$

Consider the simultaneous equations of three variables as follows.

$$
\begin{aligned}
& a x+b y+c z=c m \\
& a x+a y+f z=f m \\
& m x+p y+q z=q m
\end{aligned}
$$

Here, ratio of coefficient $\mathrm{z}=$ Ratio of their independent terms

$$
\therefore \quad \mathrm{x}=0 \text { \& } \mathrm{y}=0 \text { then } \mathrm{z}=\mathrm{m} \text {. }
$$

\section{Antyayoreva (अन्त्ययोरेव)}

The meaning of Antyayoreva is "only the last terms". i.e. while applying the formula, last two digits i.e. unit place and ten ${ }^{\text {th }}$ place digit are observed (Tirthaji, 2015). This formula is used to solve the specific types of rational expression. The specific type means: the type of equation of those whose numerator and denominator on the LHS bearing the independent terms stands in the same ratio to each other as the entire numerator and the entire denominator of the RHS stand to each other (Parajuli, 2021; Tirthaji, 2015; Bose, 2014). Consider $\frac{x^{2}+3 x+6}{x^{2}+5 x+5}=\frac{x+3}{x+5}$ where, 
$\frac{x^{2}+3 x}{x^{2}+5 x}=\frac{x(x+3)}{x(x+5)}=\frac{x+3}{x+5}=$ RHS, which satisfies the condition of the Antyayoreva. So, $\frac{x+3}{x+5}=\frac{6}{5}$, i.e., $x=-15$.

\section{Lopanasthapanabhyam (लोपनस्थापनाभ्याम)}

The meaning of 'Lopanasthapanabhyam' is 'By alternate elimination and retention'. This formula is used for factorization of $2^{\text {nd }}$ degree homogeneous and non-homogeneous polynomial functions with three or more variables. It is used for finding HCF. It is also used in solving simultaneous equations, quadratic, cubic equations etc. (Parajuli, 2021; Tirthaji, 2015; Williams, 2019).

\section{(i) Use of Lopanasthapanabhyam for factorization}

Specially, this formula is used for factorization of $2^{\text {nd }}$ degree (homogenous and nonhomogeneous) polynomials in three or more variables. Therefore, it is an important process to find the value of any variable which removes the difficulty of factorization and make the factorization simple. Consider the polynomial of $\mathrm{ax}^{2}+\mathrm{by}^{2}+\mathrm{cz}^{2}+$ $\mathrm{dxy}+$ eyz $+\mathrm{fzx}$, which is homogeneous of second degree in three variables $\mathrm{x}, \mathrm{y}, \mathrm{z}$ (Tirthaji, 2015; Williams, 2019).

For the factorization, we should apply the following steps as mentioned below (Parajuli, 2021; Tirthaji, 2015; Glover, 2013).

- Eliminate $z$ by putting $z=0$ and retain two variables $x$ and $y$. Factorize the obtained polynomial using Adyamadyena (another Vedic formula) formula.

- Similarly, eliminate $y$ by putting $y=0$ and retain $\mathrm{x}$ and $\mathrm{z}$ and factorize the obtained polynomial.

- With these two sets of factors, fill in the gaps caused by elimination process of $\mathrm{z}$ and y respectively for finding the final factors of the original expression.

Consider the homogeneous polynomial, $3 \mathrm{x}^{2}+\mathrm{y}^{2}-4 \mathrm{xy}-\mathrm{yz}-2 \mathrm{z}^{2}-\mathrm{zx}$

Putting $\mathrm{z}=0$ gives the factors $(x-y)(3 x-y)$ and putting $y=0$ gives $(x-z)(3 x+2 z)$ By filling the gaps $=(\mathrm{x}-\mathrm{y}-\mathrm{z})(3 \mathrm{x}-\mathrm{y}+2 \mathrm{z})$

$$
\therefore \quad 3 \mathrm{x}^{2}+\mathrm{y}^{2}-4 \mathrm{xy}-\mathrm{yz}-2 \mathrm{z}^{2}-\mathrm{zx}=(\mathrm{x}-\mathrm{y}-\mathrm{z})(3 \mathrm{x}-\mathrm{y}+2 \mathrm{z})
$$

Consider the second-degree non-homogeneous polynomial

$$
3 x^{2}+6 y^{2}+2 z^{2}+11 x y+7 x z+7 y z+16 x+20 y+12 z+16
$$

For non-homogeneous second-degree polynomial, we eliminate two variables at a time and retain only one variable and the independent term, each time. Then we 
obtain the result as described in the above steps. (We need one step more than the homogenous cases)

Putting $\mathrm{x}=0$ and $\mathrm{y}=0$ gives the factors $(\mathrm{z}+4)(2 \mathrm{z}+4)$; putting $\mathrm{y}=0$ and $\mathrm{z}=0$ yields $(x+4)(3 x+4)$; putting $x=0$ and $z=0$ yields $(y+2)(6 y+8)=(2 y+4)(3 y+4)$.

By filling the gaps: $(x+3 y+2 z+4)(3 x+2 y+z+4)$

$\therefore 3 x^{2}+6 y^{2}+2 z^{2}+11 x y+7 x z+7 y z+16 x+20 y+12 z+16$

$$
=(\mathrm{x}+3 \mathrm{y}+2 \mathrm{z}+4)(3 \mathrm{x}+2 \mathrm{y}+\mathrm{z}+4) \text {. }
$$

(ii) Use of Lopanasthapanabhyam to find HCF: (Parajul, 2021; Tirthaji, 2015; Williams, 2019; William, 2019)

Vedic Mathematics used the method elimination and retention to find HCF. In this method, we divide through by factors continues until the remaining numbers are coprime as explained the following examples. By this method, we eliminate highest power and lowest power of the given expression by adding or subtracting the given expression from each other. We find the HCF by removing the common factor if any from each (Parajuli, 2021; Tirthaji, 2015). For illustration, we find the HCF of the expressions $\mathrm{x}^{3}-3 \mathrm{x}^{2}-4 \mathrm{x}+12 \& \mathrm{x}^{3}-7 \mathrm{x}^{2}+16 \mathrm{x}-12$.

In addition, and subtraction columns, we should use the following steps as follows.

\begin{tabular}{c|c} 
Adding & Subtracting \\
\hline $\mathrm{x}^{3}-3 \mathrm{x}^{2}-4 \mathrm{x}+12$ & $\mathrm{x}^{3}-3 \mathrm{x}^{2}-4 \mathrm{x}+12$ \\
$\mathrm{x}^{3}-7 \mathrm{x}^{2}+16 \mathrm{x}-12$ & $\mathrm{x}^{2}-7 \mathrm{x}^{2}+16 \mathrm{x}-12$ \\
& -+-+ \\
\hline $2 \mathrm{x}^{3}-10 \mathrm{x}^{2}+12 \mathrm{x}$ & $4 \mathrm{x}^{2}-20 \mathrm{x}+24$ \\
$2 \mathrm{x}\left(\mathrm{x}^{2}-5 \mathrm{x}+6\right)$ & $4\left(\mathrm{x}^{2}-5 \mathrm{x}+6\right)$ \\
\hline$\left(\mathrm{x}^{2}-5 \mathrm{x}+6\right)$ & $\left(\mathrm{x}^{2}-5 \mathrm{x}+6\right)$ \\
$\therefore H C F=\left(x^{2}-5 x+6\right)$ &
\end{tabular}

\section{Discussions}

The illustration of Vedic formulas in the above sub-topic 2.0 is only confined to a small portion of basic algebraic issues. The paper expresses how it can be expanded from specific sections to its territorial conceptions and notions of simple algebraic instances in this discussion section. 


\section{In the case of Paravartya Yojayet}

- In terms of algebraic division, the Paravartya Yojayet formula is extremely similar to the Remainder Theorem and the Horner process of synthetic division. Horner's synthetic division method is only a minor part of the Paravartya formula, which can be expanded to circumstances when the divisor is quadratic, cubic, or any size polynomial.

- In the illustration part Paravartya formula of above sub-topic 2, the first coefficient of $\mathrm{g}(\mathrm{x})$ was unity; there was no possibility of a fractional coefficient in $\mathrm{Q}(\mathrm{x})$ being special cases. However, a lack of unity can lead to uncertainty, redundancy, and other issues. As a result, the best option will be to divide the divisor by its first coefficient right away and finish the calculation as in special cases.

- The merger formula of Paravartya Yojayet can be extended to any finite number of terms for solving equations.

- In the case of improper fractions, Paravartya Yojayet can be used by expressing the numerator as the sum of polynomial and proper fractions.

- To find the partial fraction of the expression whose denominator is repeated i.e. square, cube etc. there is slight variation in process is required by the formula Paravartya Yojayet.

\section{In the case of Sunyam Samyasamuccaye}

- It is clear that the expression $\frac{\mathrm{ax}+\mathrm{b}}{\mathrm{ax}+\mathrm{c}}=\frac{\mathrm{ax}+\mathrm{c}}{\mathrm{ax}+\mathrm{b}}$ would be linear. But the expression $\frac{\mathrm{ax}+\mathrm{b}}{\mathrm{cx}+\mathrm{d}}=\frac{\mathrm{cx}+\mathrm{d}}{\mathrm{ax}+\mathrm{b}}$ would be quadratic. It should be careful that $\mathrm{N}_{1}+\mathrm{N}_{2}$ $=\mathrm{D}_{1}+\mathrm{D}_{2}$ and $\mathrm{N}_{1}-\mathrm{D}_{1}=\mathrm{D}_{2}-\mathrm{N}_{2}$ in both cases.

- The expression of the form $\frac{2}{2 x+3}+\frac{3}{3 x+2}=\frac{1}{x+1}+\frac{6}{6 x+7}$ when $N_{1} \times D_{2}=N_{2} \times$ $\mathrm{D}_{1} \& \mathrm{~N}_{3} \times \mathrm{D}_{4}=\mathrm{N}_{4} \times \mathrm{D}_{3}$ (where $\mathrm{N}_{1}, \mathrm{~N}_{2}, \mathrm{~N}_{3}, \mathrm{~N}_{4}, \mathrm{D}_{1}, \mathrm{D}_{2}, \mathrm{D}_{3}, \mathrm{D}_{4}$ have their usual meanings) which can be changed into the (vi) ${ }^{\text {th }}$ application.

\section{In the case of Anurupye Sunyamanyat}

- The formula is especially more useful for solving simultaneous equations whose solution is complex being the large coefficients like $8906 x+45 y=73$; $1953 x+31 y=63$.

- The formula can be extended to any number of unknown quantities.

\section{In the case of Antayoreva}

- This formula is more valuable when the problem is unsolved by the formula Sunyam Samyasamuccaye even the Samuccaye are equal in the case like $(\mathrm{x}+3)$ 
$(\mathrm{x}+4)(\mathrm{x}+5)=(\mathrm{x}+1)(\mathrm{x}+2)(\mathrm{x}+9)$, which becomes $\frac{x^{2}+3 x+2}{x^{2}+9 x+20}=\frac{x+3}{x+9}$ then using antayoreva $\mathrm{x}=\frac{-7}{3}$.

\section{In the case of Lopanasthapanabhyam}

- In most cases, eliminating two of the three variables is enough to factorize the polynomials. There may arises some exceptional cases like $x^{2}+x y-2 y^{2}+$ $2 \mathrm{xz}-5 \mathrm{yz}-3 \mathrm{z}^{2}$. By putting $\mathrm{y}=0$ yields $(\mathrm{x}-\mathrm{z})(\mathrm{x}+3 \mathrm{z})$ and $\mathrm{z}=0$ yields $(\mathrm{x}-\mathrm{y})$ $(x+2 y)$. Here is confusion to take right combination of factors. As a result, if $\mathrm{x}$ is also removed, the factor will be $(-\mathrm{y}-\mathrm{z})(2 \mathrm{y}+3 \mathrm{z})$. Then there will be no mistake about which factors to use. Hence, $x^{2}+x y-2 y^{2}+2 x z-5 y z-3 z^{2}=$ $(\mathrm{x}-\mathrm{y}-\mathrm{z})(\mathrm{x}+2 \mathrm{y}+3 \mathrm{z})$.

- Formulas from the Vedas Sankalana Vyavakalanabhyam and Lopasthapanabhyam function together to find the HCF of an algebraic expression using a Vedic approach, while the traditional method uses factorization and continuous division.

\section{Conclusions}

The impression of Vedic methodologies that were more or less previously assimilated or integrated in modern mathematical systems, such as Horner's synthetic division process, Remainder theorem of polynomials, Crammer's rule, cross multiplication method to solve simultaneous equations, factorizations of polynomials, partial fractions of proper and improper rational functions. Except some cases, conventional mathematics practitioners are utterly unaware of many of the Vedic formulas mentioned in this paper. Even so, there are significant limitations to Vedic formulas in specific cases involving elementary algebraic problems.

Under the presentation, demonstration, discussion, and outcomes of this paper, the study concludes that Vedic Mathematics and its five specific Vedic formulas are more valuable and practicable to those learners who are having difficulty with elementary level algebra using traditional methods. Traditional students must use a calculator to solve numerical and algebraic problems, whereas Vedic students may solve similar problems mentally.

\section{Suggestions}

It is preferable to compare the methods to conventional approaches in order to assess their value and effectiveness. Without really using the technique, the true beauty and efficiency of these methods cannot be fully comprehended. 


\section{References}

Acharya, E. R. (2015). Nayaraj Pantaka Ganitiya Kritiharuko Addhyan (Unpublished Ph.D. Thesis). Nepal: Research Center, Nepal Sanskrit University.

Bose, S. (2014). Vedic Mathematics. New Delhi: V \& S Publishers.

Boyer, C. B. (1991). A History of Mathematics. New York: John Wiley \& Sons, Inc.

Cajori, F. (1919). A History of Mathematics. New York: The Macmillan.

Dave, S., Fletcher, M., Glover, J., Prudente, V., Prodente, V., \& Ramachandran, G. (2018). Inspirational Maths from India. IAVM, www.instavm.org. Retrieved from www.instavm.org

Glover, J. (2013). Vedic Mathematics for Schools Book-3. New Delhi: Motilal Banarasidass Pvt. Ltd.

Groza, V. S. (1968). A Survey of Mathematics; Elementary Concepts and Their Historical Development. New York: New York, Halt, Rinehart and winston.

Hoad, T. F. (1996). Oxford Concise Dictionary of English Etymology. London: Oxford University Press. doi: 10.1093/acref/9780192830982.001.0001

Menini, C., \& Oystaeyen, F. V. (2017). Abstract Algebra: A Comparative Treatment. New York: CRC Press.

Parajuli, K. K. (2021). A Study on Efficacy of Teaching Vedic Mathematics for School Level In Nepal (Unpublished Ph.D. Thesis). Kathmandu: Research Center, Nepal Sanskrit University.

Parajuli, K. K. (2021). Three Classical Methods to Find Cube Roots: A Connective Prospectives on Lilavati, Vedic and Pande's Procedures. Journal of Nepal Mathematical society, 4(1), 23-32. doi:https://doi.org/10.3126/jnms. v4i1.37110

Parajuli, K. K. (2021). Three Seperate Methods for Squaring: A Connective Prospective on Lilavati, Vedic and Trachtenberg. International Journal of Statistics and Applied Mathematics, 6(2), 43-47. doi:https://doi.org/10.22271/ maths.2021.v6.i2a.673

Parajuli, K. K., Jha, K., Acharya, S. R., \& Maskey, S. M. (2020). Connection of Paravartya Sutra with Vedic and Non-Vedic Mathematics. 4th. International Vedic Mathematics Conference. Hyderabad: IAVM, UK.

Parajuli, K. K., Jha, K., Acharya, S., \& Maskey, S. M. (2019). Vedic Sutra Sunnyam Sammya samuccaya for Solving Algebriac Equations. NCMA-2019. 7th, pp. 72-78. Butwal: Nepal Mathematical Society. 
Patwardhan, K. S., Naimpally, S. A., \& Singh, S. L. (2015). Lilavati of Vhaskaracarya. New Delhi: Motilal Banarasidass Pvt. Ltd.

Plofker, K., Imhausen, A., Robson, E., \& Dauben, J. W. (2007). The Mathematics of Egypt, Mesopotamiya, China, India, and Islam: A Source Book. (V. J. Katz, Ed.) New Jersey: Princeton University Press.

Sidhu, K. S. (1990). The Teaching of Mathematics. New Delhi: Sterling Publisher's Pvt. ltd.

Struik, D. J. (1987). A Concise History of Mathematics (Third Revised ed.). New York: Dover Publication Inc.

Tirthaji, B. K. (2015). Vedic Mathematics. (V. S. Agrawala, Ed.) New Delhi, India: Motilal Banarasidass Pvt. Ltd.

Williams, K. (2019). Discover Vedic Mathematics. Scotland: Inspiration Books, UK. Retrieved from http://www.vedicmaths.org

Williams, K. (2019). Vedic Mathematics Teacher Manual, Advanced Level. Scotland, UK: Inspiration Books. Retrieved from http://www.vedicmaths.org 